\title{
Atypical Endometrial Hyperplasia
}

National Cancer Institute

\section{Source}

National Cancer Institute. Atypical Endometrial Hyperplasia. NCI Thesaurus. Code C4654.

An endometrial hyperplasia characterized by cytologic and architectural changes which may lead to endometrial carcinoma. Despite the atypical features and possible course, there is debate on whether to consider this a neoplasm. The relationship with endometrial intraepithelial neoplasia is also unclear. 